American J. of Engineering and Applied Sciences 1 (3): 181-187, 2008

ISSN 1941-7020

(C) 2008 Science Publications

\title{
Numerical Study of the Temperature Separation in the Ranque-Hilsch Vortex Tube
}

\author{
${ }^{1}$ Saeid Akhesmeh, ${ }^{1}$ Nader Pourmahmoud and ${ }^{2}$ Hasan Sedgi \\ ${ }^{1}$ Department of Mechanical Engineering, Urmia University, Urmia, Iran \\ ${ }^{2}$ Department of Physics, Urmia University, Urmia, Iran
}

\begin{abstract}
This research has been carried out in order to provide an understanding of the physical behaviors of the flow variation of pressure and temperature in a vortex tube. A computational fluid dynamics model is used to predict the flow fields and the associated temperature separation within a Ranque-Hilsch vortex tube. The CFD model is a steady axisymmetric model (with swirl) that utilizes the standard k- $\varepsilon$ turbulence model. The second-order numerical schemes, was used to carry out all the computations. Vortex tube with a circumferential inlet stream and an axial (cold) outlet stream and a axial (hot) outlet stream was considered. Performance curves (temperature separation versus cold outlet mass fraction) were obtained for a specific vortex tube with a given inlet mass flow rate. Simulations have been carried out for varying amounts of cold outlet mass flow rates. The model results has reasonable agreement with experimental data.
\end{abstract}

Key words: Ranque-hilsch vortex tube, temperature separation, CFD model, k- $\varepsilon$ model, cold mass fraction

\section{INTRODUCTION}

Vortex tube is a simple device with no moving parts for producing hot and cold air (When compressed air flows tangentially into the vortex chamber through the inlet nozzles). Vortex tubes are used commonly for industrial purposes: to cool machinery during operation (e.g., mold tools, sewing needles and soldering), to cool workers, to test thermostats and etc., They are popular for their reliability (no moving parts), lack of maintenance and simple and inexpensive construction. The device consists of a simple circular tube, with one or more azimuthal nozzles for flow inlet and two outlets for flow exits. High pressure air, enter the tube azimuthally at one end and produces a strong vortex flow in the tube. The gas expands through the nozzle and achieves a high angular velocity, causing a vortextype flow in the tube. There are two exits to the tube: the hot exit is placed near the outer radius of the tube at the end away from the nozzle and the cold exit is placed at the center of the tube at the same end as the nozzle.

The gas is separated into two streams having different temperatures at higher and lower temperaure than the inlet gas temperature. This effect is referred to as the temperature separation effect that reported for the first time by Ranque in 1931 when he was studying processes in a dust separation cyclone ${ }^{[1]}$. His design of the vortex tube has later been improved by the German physicist $^{[2]}$, who arranged a diaphragm at the cold gas site and suggested that angular velocity gradients in the radial direction give rise to frictional coupling between different layers of the rotating flow resulting in the migration of energy via shear work from the inner layers to the outer layers. Other investigators have attributed the energy separation to work transfer via compression and expansion. Several variations of this theory are described in the literature, differing according to the mechanism that drives the fluid motion. Harnett and Eckert ${ }^{[3]}$ invoked turbulent eddies, Ahlborn and Gordon ${ }^{[4]}$ described an embedded secondary circulation and Stephan et al. ${ }^{[5]}$ proposed the formation of Gortler vortices on the inside wall of the vortex tube that drive the fluid motion. Kurosaka ${ }^{[6]}$ reported the temperature separation to be a result of acoustic streaming effect that transfer energy from the cold core to the hot outer annulus. Gutsol ${ }^{[7]}$ hypothesized the energy separation to be a consequence of the interaction of micro volumes in the vortex tube. Despite all the proposed theories, none has been able to explain the temperature separation effect satisfactorily. Recent efforts have successfully utilized computational fluid dynamics (CFD) modeling to explain the fundamental principles behind the energy separation produced by the vortex tube. Frohlingsdorf et al. ${ }^{[8]}$ modeled the flow within a vortex tube using a CFD solver that included compressible and turbulent

Corresponding Authhor: Saeid. Akhesmeh, Department of Mechanical Engineering, Urmia University, Urmia, Iran 
effects.The numerical predictions qualitatively predicted the experimental results presented by Bruun $^{[9]}$. Ahlborn et al. ${ }^{[10,11]}$ shown the dependence of vortex tube performance on normalized pressure drop with a numerical model. Aljuwayhel et al ${ }^{[12]}$ utilized a fluid dynamics model of the vortex tube to understand the process that drive the temperature separation phenomena. They reported that the energy separation exhibited by the vortex tube is due to the work transfer caused by a torque produced by viscous shear acting on a rotating control surface that separates the cold flow region and the hot flow region. Skye et al. ${ }^{[13]}$ used a model similar to that of ${ }^{[12]}$. They also measured the inlet and outlet temperatures of the vortex tube and compared with the predictions from the fluid dynamics model. The temperature separation predicted by their model for commercially available vortex tube was found to be in reasonable agreement to the experimental measurements. As the flow inside vortex tube is axisymmetric, steady state and employs the standard k$\varepsilon$ turbulence model. A part of sector is taken for analysis giving cyclic boundary condition. The threedimensional model showing the boundary regions used in calculation is shown in Fig. 1. A compressible form of the Navier-Stokes equation together with the standard $k-\varepsilon$ model by second order upwind for momentum and turbulence equations and the quick numerical schemes for energy equation has been used to simulate the phenomenon of flow pattern and temperature separation ration in a Ranque-Hilsch vortex tube with 6 circumferential inlet port and the cold and hot exit are axial orifices with areas of $30.2 \mathrm{~mm}^{2}$ and $95.0 \mathrm{~mm}^{2}$ respectively (as shown in Fig. 1). That has a good conformability with available experimental data.

Governing equation: The compressible turbulent flows in the vortex tube are governed by the conservation of mass, momentum and energy equations. The mass and momentum conservation and the state equation are solved as follows:

$$
\begin{gathered}
\frac{\partial}{\partial t}(\rho)+\frac{\partial}{\partial x_{j}}\left(\rho \tilde{u}_{j}\right)=0 \\
\frac{\partial}{\partial t}\left(\rho u_{i}\right)+\frac{\partial}{\partial x_{j}}\left(\rho \tilde{u}_{j} u_{i}-\tau_{i j}\right)=-\frac{\partial p}{\partial x_{i}} \\
p=\rho R T
\end{gathered}
$$

Turbulence model: Flow in the vortex tube is highly turbulent. The steady state assumption and practical considera-tions indicate that a turbulence model must

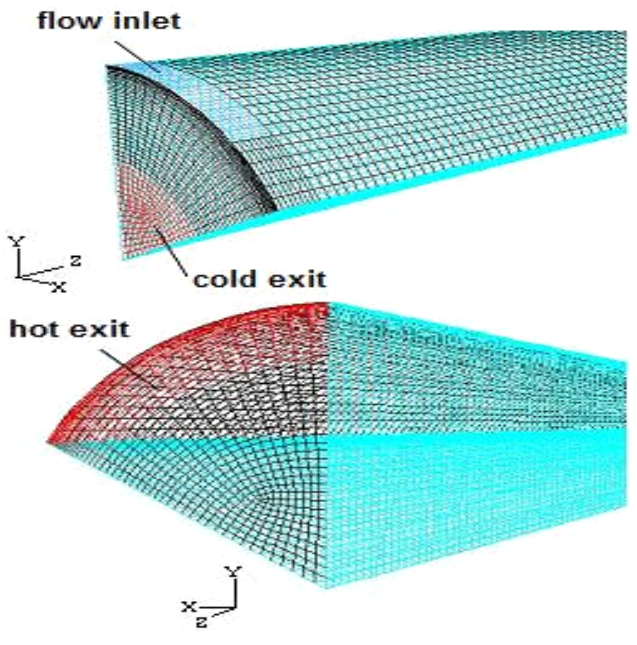

Fig. 1: Three-dimensional model of vortex tube in sector

be employed to represent its effects. The turbulence kinetic energy, kand its rate of dissipation, $\varepsilon$ are obtained from the following transport equations:

$$
\begin{aligned}
& \frac{\partial}{\partial t}(\rho \mathrm{k})+\frac{\partial}{\partial \mathrm{x}_{\mathrm{i}}}\left(\rho \mathrm{ku} \mathrm{u}_{\mathrm{i}}\right)= \\
& \frac{\partial}{\partial \mathrm{x}_{\mathrm{j}}}\left[\left(\mu+\frac{\mu_{\mathrm{t}}}{\sigma_{\mathrm{k}}}\right) \frac{\partial \mathrm{k}}{\partial \mathrm{x}_{\mathrm{j}}}\right]+\mathrm{G}_{\mathrm{k}}+\mathrm{G}_{\mathrm{b}}-\rho \varepsilon-\mathrm{Y}_{\mathrm{M}}
\end{aligned}
$$

and

$$
\begin{aligned}
\frac{\partial}{\partial \mathrm{t}}(\rho \mathrm{k})+\frac{\partial}{\partial \mathrm{x}_{\mathrm{i}}}\left(\rho \mathrm{ku}_{\mathrm{i}}\right)= & \frac{\partial}{\partial \mathrm{x}_{\mathrm{j}}}\left[\left(\mu+\frac{\mu_{\mathrm{t}}}{\sigma_{\varepsilon}}\right) \frac{\partial \varepsilon}{\partial \mathrm{x}_{\mathrm{j}}}\right] \\
& +\mathrm{C}_{1 \varepsilon} \frac{\varepsilon}{\mathrm{k}}\left(\mathrm{G}_{\mathrm{k}}+\mathrm{C}_{3 \varepsilon} \mathrm{G}_{\mathrm{b}}\right)-\mathrm{C}_{2 \varepsilon} \rho \frac{\varepsilon^{2}}{\mathrm{k}}
\end{aligned}
$$

In these equations, $G_{k}$ represents the generation of turbulence kinetic energy due to the mean velocity gradients, $G_{b}$ is the generation of turbulence kinetic energy due to buoyancy, $\mathrm{Y}_{\mathrm{M}}$ represents the contribution of the fluctuating dilatation in compressible turbulence to the overall dissipation rate, $\mathrm{C}_{1 \varepsilon}, \mathrm{C}_{2 \varepsilon}$ and $\mathrm{C}_{3 \varepsilon}$ are constants. $\sigma_{\mathrm{k}}$ and $\sigma_{\varepsilon}$ are the turbulent prandtl numbers for $\mathrm{k}$ and $\varepsilon$, respectively. The turbulent (or eddy) viscosity, $\mu_{\mathrm{t}}$ is computed by combining $\mathrm{k}$ and $\varepsilon$ as follows:

$$
\mu_{\mathrm{t}}=\rho \mathrm{C}_{\mu} \frac{\mathrm{k}^{2}}{\varepsilon}
$$

where, $\mathrm{C} \mu$ is a constant. 


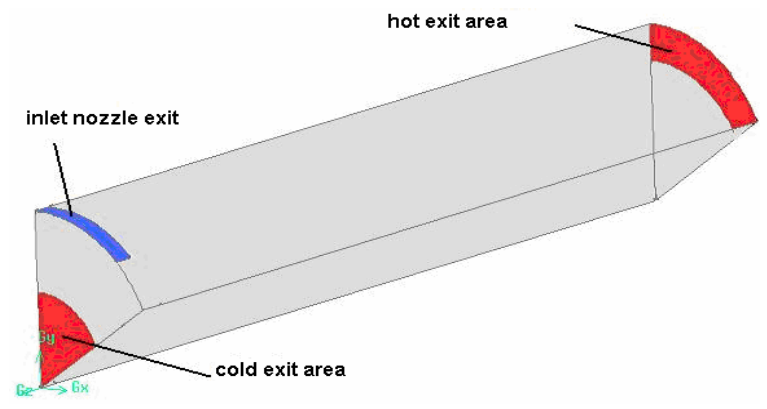

Fig. 2: Schematic of the computational domain

Schematic of the problem geometry: Figure 2 shows the computational domain for the vortex tube geometry considered in this study. Basic assumptions for all the computations of the particular vortex-tube flows were made as follows: A circumferential pressurized gas inlet and two axial orifice for cold and hot stream, supersonic flow inside the vortex tube and ideal gas (arbitrary air). Since the nozzle consists of 6 straight slots, the CFD model assumed to be an rotational periodic flow and only a sector of the flow domain with angle $60^{\circ}$ needs to be considered throughout and special treatment for the flow at the inlet must be made for the computations.

The length and the radius of the vortex tube are set to 106 and $5.7 \mathrm{~mm}$, respectively. The height of each slot is $0.97 \mathrm{~mm}$ and the width is $1.41 \mathrm{~mm}$. The cold and hot exits are axial orifices with areas of 30.2 and $95 \mathrm{~mm}^{2}$, respectively. Boundary conditions for the model were determined based on the experimental measurements by Skye et al. ${ }^{[13]}$. The inlet is modeled as a mass flow inlet; the total mass flow rate, stagnation temperature and direction vector were specified and fixed at $8.35 \mathrm{~g} \mathrm{sec}^{-1}, \quad 294.2 \mathrm{~K}, \mathrm{~V}_{\mathrm{r}}=0.25 \mathrm{~V}_{\mathrm{n}}$, $\mathrm{V}_{\mathrm{e}}=0.97 \mathrm{~V}_{\mathrm{n}}$, where $\mathrm{V}_{\mathrm{n}}$ represents the total velocity vector, while $\mathrm{V}_{\mathrm{r}}$ and $\mathrm{V}_{\mathrm{e}}$ denote the radial and tangential components of velocity, respectively. The static pressure at the cold exit boundary was fixed at experimental measurements pressure. The static pressure at the hot exit boundary was adjusted to vary the cold fraction. A no-slip boundary condition is enforced on all walls of the vortex tube.

\section{RESULTS AND DISCUSSION}

The temperature separation obtained from the present calculations were compared with the experimental and computational results of ${ }^{[13]}$. As shown in Fig. 3 and 4 , the hot exit temperature difference $\Delta T_{h, i}$ predicted by the model is in good agreement with the experimental results. Prediction of the cold exit

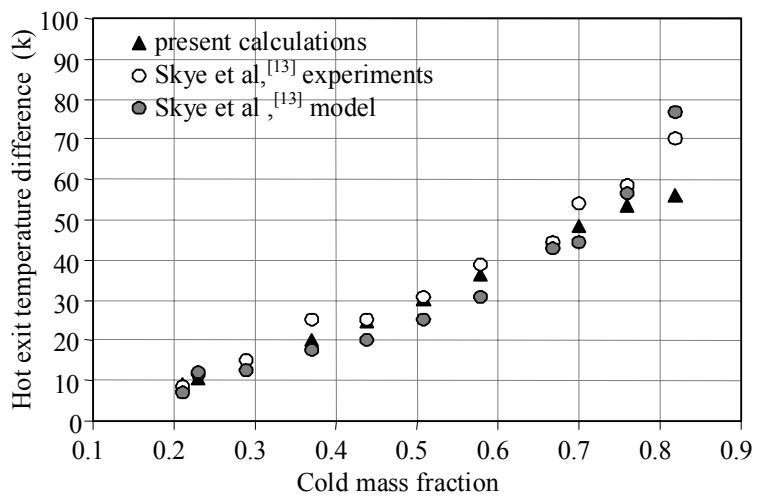

Fig. 3: Hot exit temperature difference as a function of cold mass fraction

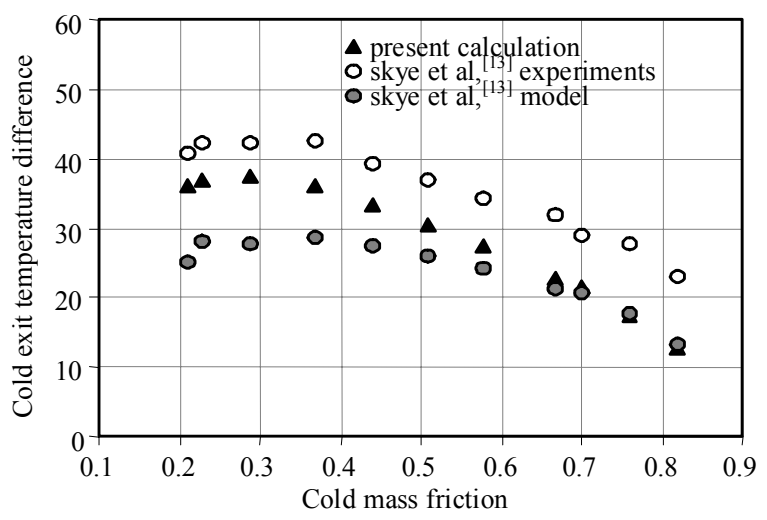

Fig. 4: Cold exit temperature difference as a function of cold mass fraction

temperature difference $\Delta \mathrm{T}_{\mathrm{i}, \mathrm{c}}$ is found to lie in between the experimental and computational results of ${ }^{[13]}$. Compared to the present calculations $\mathrm{k}-\varepsilon$ model predictions with computational results of Skye, clearly observed that the hot exit temperature difference $\Delta \mathrm{T}_{\mathrm{h}, \mathrm{i}}$ simulated by both the models were close to the experimental results. Though both the models underpredicted the cold exit temperature difference $\Delta \mathrm{T}_{\mathrm{i}, \mathrm{c}}$, the predictions from the present model were found to be closer to the experimental results.

In the CFD model, the cold exit pressure boundary condition was specified at the measured cold exit pressure and the hot exit pressure was iteratively specified until the experimentally measured cold fraction was achieved. As shown in Fig. 5, the model generally over-predicted the hot exit pressure required for a given cold fraction, however, the general trend agrees well.

The rate of energy separation provides another measure of the vortex tube performance. The rates of 


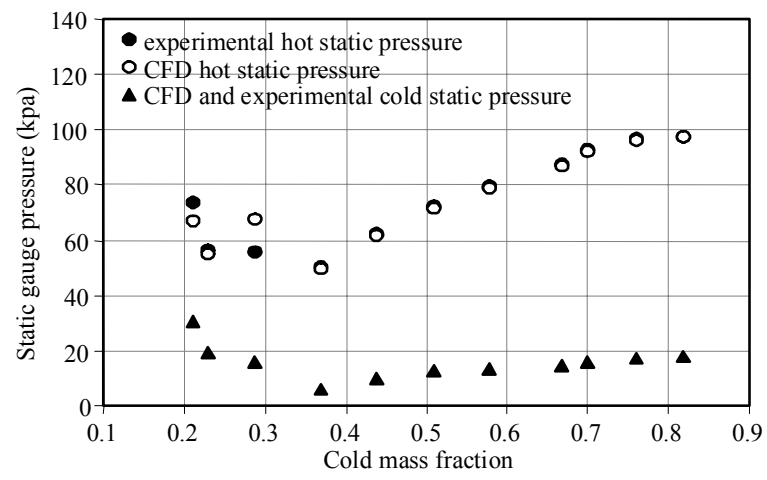

Fig. 5: FD model predictions of hot and cold exit static pressure as a function of the cold fraction

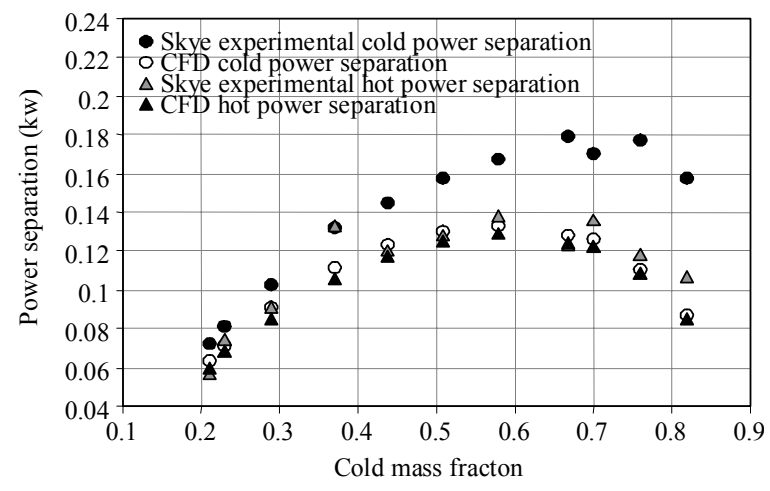

Fig. 6: Predicted hot and cold power separation rate as a function of cold fraction

energy separation ( $\dot{\mathrm{Q}}_{\mathrm{c}}$ and $\dot{\mathrm{Q}}_{\mathrm{h}}$ ) were evaluated based on the experimental data and the CFD predictions and are shown in Fig. 5 as a function of the cold fraction. Again, the model consistently under- predicts the separation effect in the vortex tube, however, the shape of the curve and the qualitative trends agree very well. Both the experimental data and the model show maximum power separation with a cold fraction of about 0.65 .

Figure 7 shows the streamlines in three dimensional space associated with the flow inside the vortex tube. Figure $8 \mathrm{a}$ and $\mathrm{b}$ show, respectively, contour plots of the predicted static and total temperature by the k- $\varepsilon$ model. It is seen that, for static temperature contours in Fig. 8a temperature gradients are high in the region near the tube wall and are small in the core region. The static temperature variations across the tube are seen to be considerably smaller than those found for the total temperature. It is of interest to note that the entire flow, except for the outer annular ring, is at a total temperature lower than the inlet temperature, $T_{\text {in }}$.

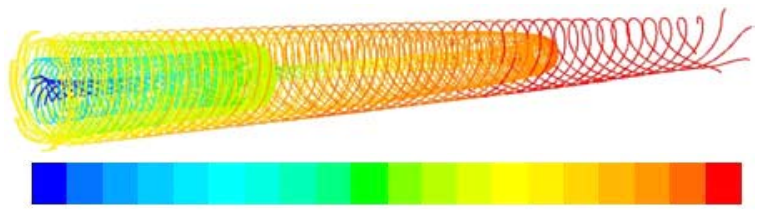

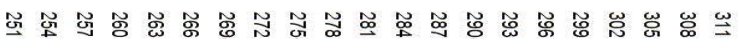

Fig. 7: Streamlines inside of vortex tube in threedimensional space, colored by total temperature

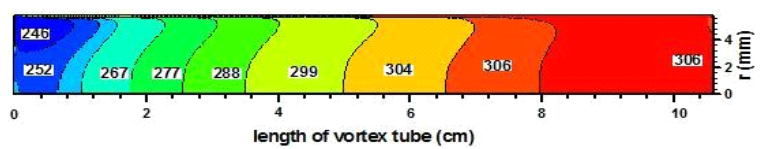

(a)

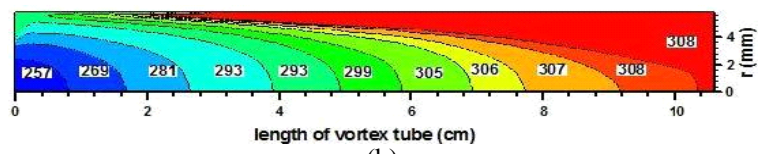

(b)

Fig. 8: (a): Contours of static temperature, (b): Contours of total temperature

The separation of the total temperature field into regions of high energy (high total temperature) along the tube wall and low energy is evident in Fig. 8b which shows that the total temperature is a minimum in the central region. The separation effect or temperature difference for the total temperature is large near the core of the inlet region and decreases as the exit is approached.

Figure 9 shows the radial profiles of the axial velocity $u_{x}$ at different axial locations $(x=25,50$ and $75 \mathrm{~mm}$ ) for specified cold mass fraction equal 0.2884 . The maximum axial velocity is near the tube wall and the direction of the flow near the wall is towards the hot end exit and the direction of the flow along the axis is towards the cold end exit. It was observed that the maximum value of the axial velocity decreased with increasing axial distance. At axial locations of 25, 50 and $75 \mathrm{~mm}$ the maximum axial velocity was found to be 81,68 and $52 \mathrm{~m} \mathrm{~s}^{-1}$ respectively. The axial velocity profiles show that the flow reversal takes place at about $2.5 \mathrm{~mm}$ from the center of the tube. The axial velocity in the cold core is directed towards the cold end exit. The axial velocity in the cold core was found to increase with a decrease in the axial distance.

Figure 10 shows the radial profiles for the swirl velocity $\mathrm{u}_{\theta}$ at different axial locations $(\mathrm{x}=25,50$ and $75 \mathrm{~mm}$ ). Comparing the velocity components, it is observed the swirl velocity has twice the magnitude of 


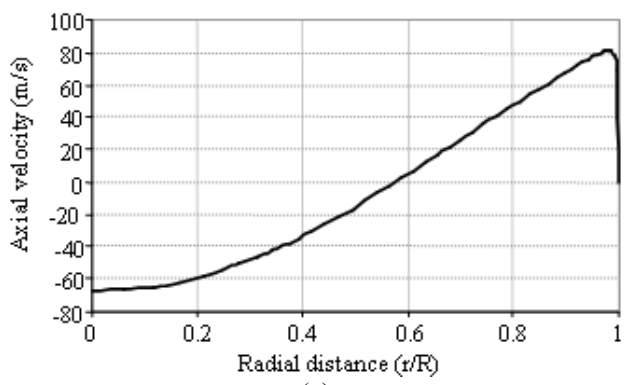

(a)

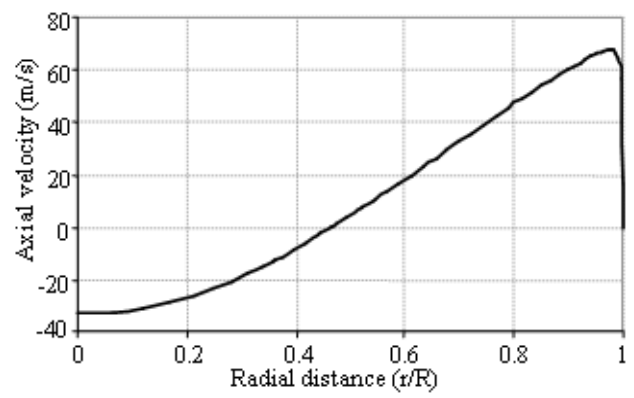

(b)

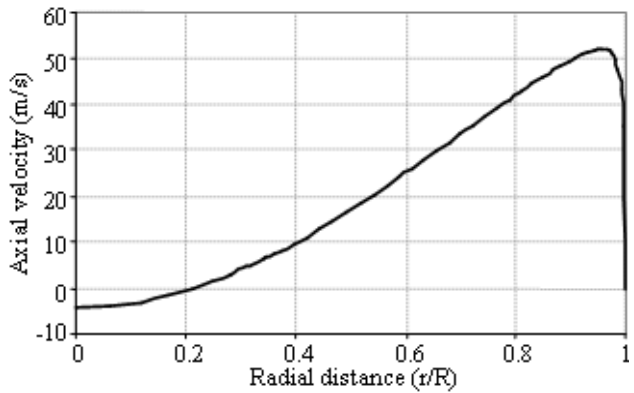

(c)

Fig. 9: Radial profiles of axial velocity at various axial positions, (a): $x=25 \mathrm{~mm},(\mathrm{~b}): \mathrm{x}=50 \mathrm{~mm}$, (c): $\mathrm{x}=75 \mathrm{~mm}$

the axial velocity. The magnitude of the swirl velocity decreases towards the hot end exit. The radial profile of the swirl velocity indicates a free vortex near the wall and the values become negligibly small at the core, which is in conformity with the observations of ${ }^{[6,7]}$.

The radial velocity $u_{r}$ is shown in Fig. 11 which that is significantly low in magnitude compared to the $\mathrm{u}_{\theta}$ and $\mathrm{u}_{\mathrm{x}}$ components. It has a negative component at the inlet zone towards the tube axis and a positive component up to the tube wall. This indicates possibilities of energy transfer in the radial plane.

The axial and swirl (but not the radial) velocity profiles obtained at different axial locations of the vortex tube are in good conformity with those observed by $^{[7,14]}$.

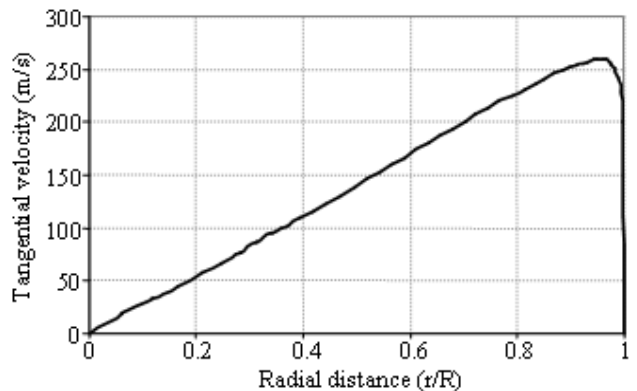

(a)

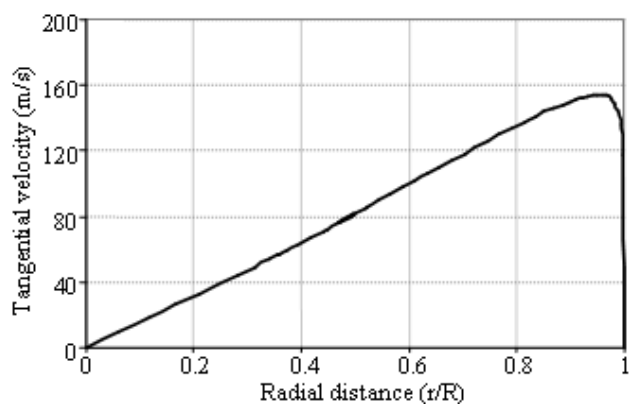

(b)

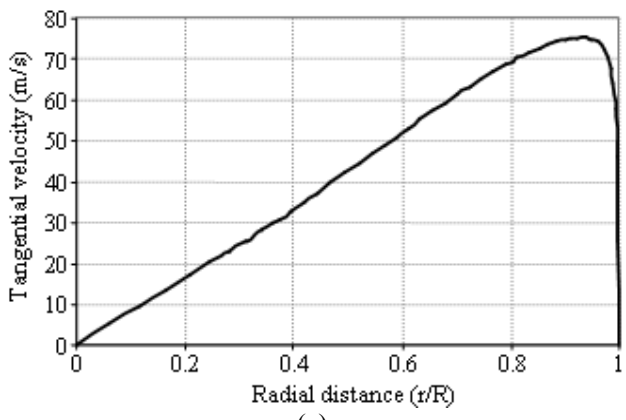

(c)

Fig. 10: Radial profile of swirl velocity at various axial position, (a): $x=25 \mathrm{~mm},(\mathrm{~b}): \mathrm{x}=50 \mathrm{~mm}$, (c): $\mathrm{x}=75 \mathrm{~mm}$

Radial profiles of the total temperature $T_{\text {total }}$ at different axial location $(\mathrm{x}=25,50$ and $75 \mathrm{~mm})$ are presented in Fig. 12. The maximum total temperature was observed to exist near the periphery of the tube wall. At the tube wall the total temperature is found to decrease, this is due to the no slip boundary condition at the tube wall. In add-ition to the radial profiles of the static temperature $\mathrm{T}_{\text {static }}$ at different axial locations $(x=25,50$ and $75 \mathrm{~mm})$ are shown in Fig. 13. The static temperature variation is essentially similar to that of the total temperature, however, the static temperature values are lower than the total values near the outer periphery of the vortex tube. The predicted temperature profiles are a result of the kinetic energy distribution in 


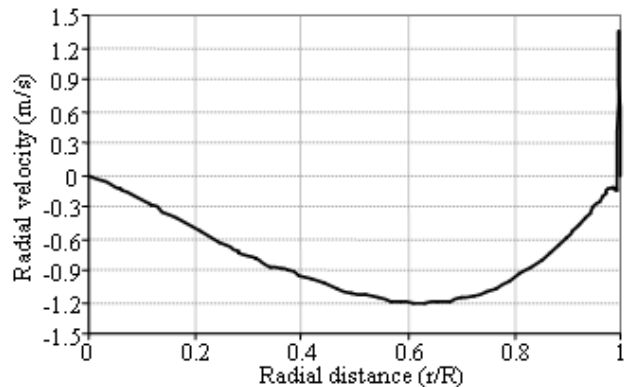

(a)

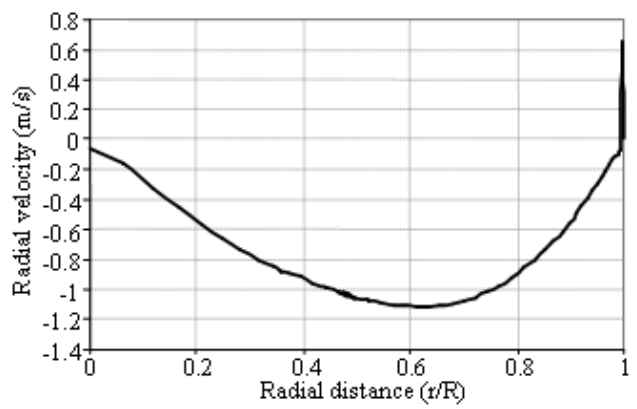

(b)

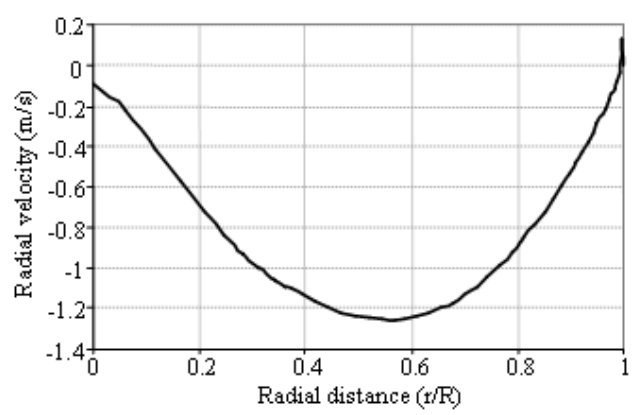

(c)

Fig. 11: Radial profile of radial velocity at various axial position, (a): $x=25 \mathrm{~mm},(\mathrm{~b}): \mathrm{x}=50 \mathrm{~mm}$, (c): $x=75 \mathrm{~mm}$

the vortex tube. The fluid at the core of the vortex tube has very low kinetic energy due to the minimum swirl fluid velocity at the central zone of the tube. From the swirl velocity profiles Fig. 10. it was observed that the swirl velocity had almost negligible value at the core of the vortex tube.

Thus the swirl velocity being the major component. Comparing the total temperature and the swirl velocity profiles (Fig. 12 and 10) show that the low temperature zone in the core coincides with the negligible swirl velocity zone. The static temperature profiles (Fig. 12) shows an increase of the temperature values towards the periphery.

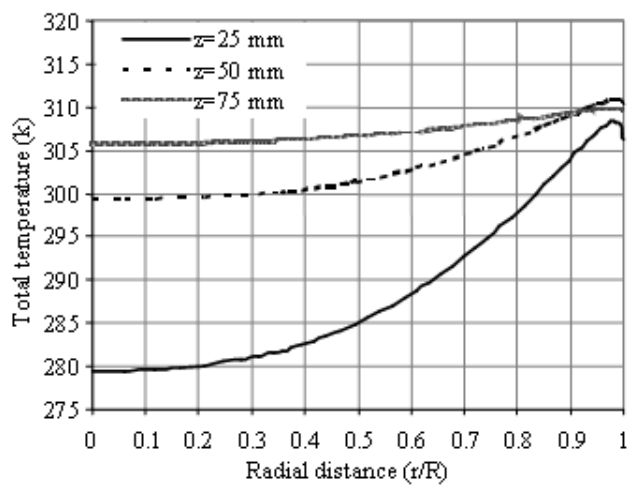

Fig. 12: Radial profile of total temperature at various axial position

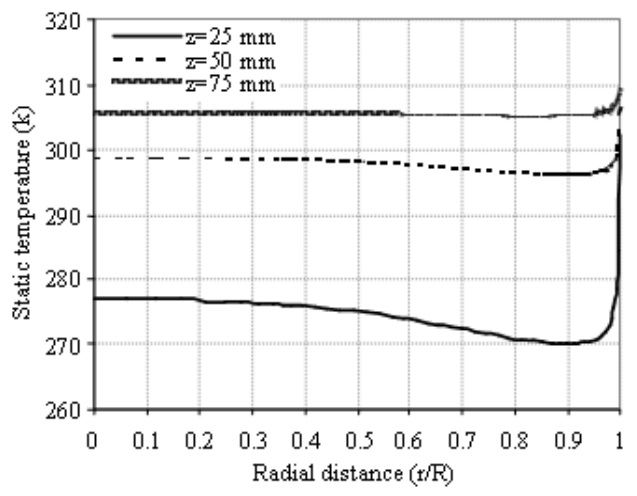

Fig. 13: Radial profile of static temperature at various axial position

\section{CONCLUSION}

A numerical computations have been carried out to predict compressible vortex tube flow. In this approach it has been assumed a axisymmetric geometry and steady state flow, so that for exhibition of turbulent flow structure of flow inside vortex tube the standard k$\varepsilon$ turbulence model is employed. Simulations were conducted for differ- rent cold mass fractions by changing the hot end pressure. The profiles indicated a hot peripheral flow and a reversing cold inner core flow together with a small secondary circulation near the cold exit. The radial velocity profile indicated that there existed a possibility of energy separation in the radial direction. The particle traces indicated that the flow entering through the upper part of the inlet constitutes the cold inner core flow and the flow entering through the lower part of the inlet comprises the hot peripheral flow. The effects of cold mass fraction on the temperature separation effect were studied. The cold 
mass fraction was varied by varying the hot exit pressure.

The hot exit temperature separation was observed to increase with an increase in the cold mass fraction. The maximum hot exit temperature separation was found to be for a cold mass fraction of 0.81. Apart from the cold mass fraction range of 0.2-0.4 the cold exit temperature separation was found to decrease with an increase in the cold mass fraction. The predictions from the numerical model were compared with experimental results of Skye et al. ${ }^{[13]}$ Comparing the present $\mathrm{k}-\varepsilon$ model and the Skye model of Skye predictions, it was found that the temperature separations predicted by the present CFD model was closer to the experimental results. the general trends of the total temperature separations (hot and cold exit) predicted by the model were found to be in good agreement with the experimental results.

\section{REFERENCES}

1. Ranque, G.J., 1933. Experiences sur la detente giratoire avec simultanes d'un echappement d'air chaud et d'un enchappement d'air froid. J. Phys. Radium., 4: 112-114.

2. Hilsc, R., 1946. Die expansion von gasen im zentrifugalfeld als kälteproze. Z. Naturforschung, 1: 208-214.

3. Harnett, J. and E. Eckert, 1957. Experimental study of the velocity and temperature distribution in a high velocity vortex-type flow. Trans. ASME, 79: 751-758.

4. Ahlborn, B. and J. Gordon, 2000. The vortex tube as a classical thermodynamic refrigeration cycle. J. Appl. Phys., 88: 3645-653.
5. Stephan,K., S. Lin, M. Durst, F. Huang, D. Seher, 1983. An investigation of energy separation in a vortex tube. Int. J. Heat Mass Transfer, 26: 341-348.

6. Kurosaka, M., 1982. Acoustic streaming in swirling flows. J. Fluid Mech., 124: 139-172.

7. Gutsol, A.F., 1997. The ranque effect, Phys. Uspekhi, 40: 639-658.

8. Frohlingsdorf, W.and H. Unger, 1999. Numerical investigations of the compressible flow and the energy separation in the ranque-hilsch vortex tube. Int. J. Heat Mass Transfer, 42: 415-422.

9. Bruun, H.H., 1969. Experimental investigation of the energy separation in vortex tubes. J. Mech. Eng. Sci., 11: 567-582.

10. Ahlborn, B., J.U. Keller, R. Staudt, G. Treitz and R. Rebhan, 1994. Limits of temperature separation in a vortex tube. J. Phys. D: Appl. Phys., 27: 480-488.

11. Ahlborn, B., J. Camire and J.U. Keller, 1996. Lowpressure vortex tubes. J. Phys D: Appl. Phys., 29: 1469-1472.

12. Aljuwayhel, N.F., G.F. Nellis and S.A. Klein, 2005. Parametric and internal study of the vortex tube using a CFD model. Int. J. Refrig., 28: 442-450.

13. Skye, H.M., G.F. Nellis and S.A. Klein, 2006. Comparison of CFD analysis to empirical data in a commercial vortex tube. Int. J. Refrig., 29: 71-80.

14. Behera, U., P.J. Paul, S . Kasthurirengan, R. Karunanithi, S.N. Ram, K. Dinesh and S. Jacob, 2005. CFD analysis and experimental investigations towardsoptimizing the parameters of ranque-hilsch vortex tube. Int. J. Heat Mass Transfer, 48: 1961-1973. 